\title{
From emergency remote teaching to hybrid NUflex: a collaborative approach to developing faculty into learning designers
}

\section{Rachel C. Plews}

Northeastern University, USA

Michael Sweet

Northeastern University, USA

Lindsey Sudbury

Northeastern University, USA

Will Malan

Northeastern University, USA

Clair Waterbury

Northeastern University, USA

Jesse Savage

Northeastern University, USA

Erin Provensal

Northeastern University, USA

Maximo Chavez

Northeastern University, USA

Keywords: hyflex; Covid-19; resilient teaching; faculty development.

\section{The challenge}

In the Spring of 2020, nearly all universities faced the unprecedented challenge of moving to emergency remote teaching during the Covid-19 pandemic. Northeastern University introduced Hybrid NUflex as their approach to ensuring academic continuity for students while attempting to welcome as many students as possible back to campus for a typical residential university learning experience in Autumn 2020. This approach required a shift in thinking from 
emergency remote teaching to a more intentionally planned design that would provide an equitable learning experience for both on-ground and remote learners. In addition to thinking about content delivery, faculty members also needed to familiarise themselves with the technologies they would be using in the physical space to connect all learners during class time.

Therefore, our main challenge was to support faculty members in adapting their course design and delivery to reach all learners regardless of teaching modality. We viewed this challenge as a triad consisting of general pedagogical challenges, the integration of various technologies for course design and delivery (e.g., Canvas, Zoom, and other platforms), and the challenge of learning how to use the hardware in the physical classrooms (e.g., camera and microphone systems). Layered on top was the learning and development challenge of turning faculty, many of whom had only taught in traditional face-to-face courses prior to Autumn 2020, into learning designers, when the disruption of the pandemic diminished their available energy and attention.

\section{The response}

In response to this triad of challenges, the Center for Advancing Teaching and Learning Through Research (CATLR) Academic Technologies (AT), and Digital University Solutions (DigiU) worked together to develop a survey for students and faculty about their experiences in the Autumn 2020 term, analyse the results, and deliver a series of Back in the Classroom Bootcamp workshops that targeted areas of concern. We delivered 16 sessions in December 2020 and January 2021 with a total of 239 participants. The first two hours of the three-hour Bootcamp consisted of a workshop on active learning, an overview of the platforms needed for a successful class using AT, and a demonstration from DigiU on the features of the classroom technology. These components align with the need for both support on design and support on delivery, the defining characteristic of the Hyflex teaching modality (Beatty, 2019; Smith, Maiden and Abinader, 2019). During the last hour of the Bootcamp, faculty were assigned to work in pairs along with an Instructional Assistant in the specific NUflex design room that they would be teaching in during the semester to experiment and try out what they learned with a peer. 


\section{Recommendations}

Our recommendations are divided into two categories - recommendations that are focused on supporting course (re)design that is resilient across modalities and recommendations for cross-unit collaborations on faculty support initiatives.

\section{Recommendations for supporting resilient course design}

Hybrid Flexible (Hyflex) learning design evolved from traditional online learning (mainly asynchronous interactions) and blended approaches (synchronous activities in addition to asynchronous content). The Hyflex design, built on the principles of Learner Choice, Equivalency, Reusability, and Accessibility, allows students to choose whether to attend classes face-to-face or online, synchronously, or asynchronously (Beatty, 2019). While this flexibility is often cited as one of the main benefits for students (Talbert, 2020; Kohnke and Moorhouse, 2021), it also requires a shift in how the faculty member approaches course design and delivery. This shift can be considered similar to the flipped classroom approach, which represents a change in how we think about the use of time for teaching and learning. Knowledge transfer, which traditionally takes place during a face-to-face lecture, now occurs asynchronously prior to a synchronous class session where time is used for activities requiring higher level thinking skills including consensus-building, question-and-answer sessions, peer review, collaborative project work, and presentations (Hutchings and Quinney, 2015; Farmer, 2018; Boettcher and Conrad, 2021).

For our approach to course design recommendations, itemised below, we combined what has been shared about Hyflex delivery with survey data from students about what was and was not working for them during the autumn semester.

1. Propose solutions that will permit a seamless pivot between modalities as often as needed. The Hyflex principle of Equivalency tells us that learning objectives should be the same regardless of modality, while instructional objectives may shift based on 
participation mode or delivery modality (Beatty, 2019). This aligns with Talbert's (2020) recommendation that we can no longer focus on one modality (face-to-face or online) when supporting faculty course design.

2. Use the learning management system as a consistent platform for course materials, resources, and communication for learners. The LMS is a great 'home base' for courses in any modality and a consistent structure and presence will help to facilitate any pivots during the semester. We recommended that faculty consider recording their courses and including the recordings along with any files or resources covered in the class session. All assessments were also integrated into the Canvas course, with the week's work aggregated into a module with due dates included. This helps students stay on track without in-classroom cues.

3. Encourage faculty members to identify ways to build a sense of community and belonging for learners. As faculty members are designing their courses, it is increasingly important for them to consider using synchronous polling, chat, and breakout room group activities to help students remain connected regardless of modality or an unanticipated pivot. Garrison (2009) tells us that in addition to teaching presence and cognitive presence, social presence is an essential part of any educational experience.

In addition to our recommendations on meeting the pedagogical challenges faced by faculty members, we considered feedback from faculty on the Bootcamp support model to improve future support initiatives. This feedback indicated that their levels of confidence for teaching in the NUflex modality grew after attending the session. The participants most valued the balance of application of active learning strategies to the NUFlex context as well as the hands-on experience in real classroom settings.

Based on these findings and our experiences as facilitators, when developing and managing cross-unit collaborations, we recommend that learning designers and support teams identify the related challenges and provide one integrated solution to address them. To encourage faculty to adopt new practices, focus on the impact these changes might have on student learning, providing evidence to support the practices. Finally, because universities may 
Plews, Sweet, Sudbury, Malan, Waterbury,

Savage, Provensal and Chavez
From emergency remote teaching to hybrid NUflex: a collaborative approach to developing faculty into learning designers

struggle with standardising technology across their many classrooms, we recommend that instructors are offered practise with the specific type of room in which they would be teaching.

\section{References}

Beatty, B. J. (2019) Hybrid-flexible course design: implementing student directed hybrid classes. Provo, Utah: EdTech Books.

Boettcher, J. V. and Conrad, R. M. (2021) The online teaching survival guide: simple and practical pedagogical tips. San Francisco, CA: John Wiley \& Sons.

Farmer, R. (2018) 'The what, the how and the why of the flipped classroom', Innovative Practice in Higher Education, 3(2), pp.14-31.

Garrison, D. R. (2009) 'Communities of inquiry in online learning', in Rogers, P., Berg, G., Boettcher, J., Howard, C., Justice, L. and Schenk, K. (eds.) Encyclopedia of Distance Learning. $2^{\text {nd }}$ end. Hershey, PA: IGI Global, pp. 352-355. http://doi:10.4018/978-160566-198-8.ch052.

Hutchings, M. and Quinney, A. (2015) 'The flipped classroom, disruptive pedagogies, enabling technologies and wicked problems: responding to "the bomb in the basement"', Electronic Journal of e-learning, 13(2), pp.106-119.

Kohnke, L. and Moorhouse, B. L. (2021) 'Adopting HyFlex in higher education in response to COVID-19: students' perspectives', Open Learning: The Journal of Open, Distance and e-Learning, pp.1-14. https://doi.org/10.1080/02680513.2021.1906641.

Smith, T., Maiden III, E. and Abinader, M. (2019) 'Using students' perceptions of online teaching and learning to inform faculty development', International Journal on ELearning, 18(3), pp.301-330. 
Talbert, R. (2020) Research report: experiencing the hyflex model. Available at: https://rtalbert.org/research-report-experiencing-the-hyflex-model// (Accessed: 24 September 2021).

\section{Author details}

Rachel Plews is an Associate Director in the Center for Advancing Teaching and Learning Through Research (CATLR) at Northeastern University. Rachel has over 15 years experience working as both a faculty member and an educational developer in higher education in the US and in Europe. Her interests are in online learning, adult and lifelong learning, and the Scholarship of Teaching and Learning (SoTL).

Michael Sweet is Director of Design and Integration in the Center for Advancing Teaching and Learning through Research (CATLR) at Northeastern University. CATLR supports educators of every kind across the global network of Northeastern campuses as they evolve and innovate in their teaching practices. Michael is drawn to the structures and experience of peer-powered learning: from Team-Based Learning in the classroom, to workshops and discussions that build authentic community, to year-long Scholarship of Teaching and Learning (SoTL) educator cohort programs.

Lindsey Sudbury is Director of Academic Technologies at Northeastern University where she works to support the evolution of a learning environment that is responsive to teaching and learning needs. Her interests include connected systems, university technology governance, accessibility, and supporting technology-enabled learning experiences filled with a variety of meaningful and purposeful engagements.

Will Malan is an adult educator with a penchant for creating meaningful, memorable experiences. His roots are in Penn State's Shaver's Creek Environmental Center, where he taught all ages about the natural world. Will now focuses on the corporate environment, instructing on principles that help employees grow and gain skills that improve their daily life. 
Plews, Sweet, Sudbury, Malan, Waterbury,

Savage, Provensal and Chavez
From emergency remote teaching to hybrid NUflex: a collaborative approach to developing faculty into learning designers

Clair Waterbury is the Assistant Director of Teaching and Learning with Technology in Academic Technologies at Northeastern University. Clair has over 15 years of experience in higher education and K-12 education, specialising in instructional technology and learning analytics.

Jesse Savage is an Academic Instructional Technologist on the Academic Technologies team at Northeastern University with 15 years of experience in technology and media. His area of interest is working with faculty to leverage technology in the classroom to enhance the student experience, creating thoughtful and creative content through digital media, and prospecting new technologies.

Erin Provensal is an Academic Instructional Technologist at Northeastern University. Her passions include using technology to enhance the learning experience through thoughtfully integrating technologies into teaching, training, and online learning.

Maximo Chavez is a Digital Solutions Analyst who works with his team to create content and knowledge for the Northeastern community. His interests include testing new software/hardware and promoting solutions for a greater digital experience. 